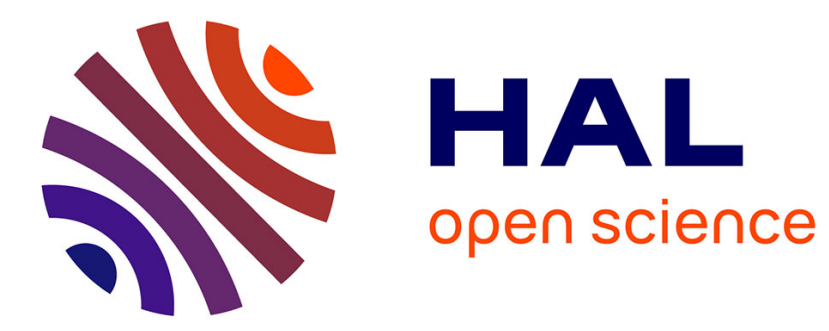

\title{
Effect of Ce and Sb on Primary Graphite Growth in Cast Irons
}

\author{
Koenraad Theuwissen, Jacques Lacaze, Lydia Laffont-Dantras, Julien \\ Zollinger, Dominique Daloz
}

\section{To cite this version:}

Koenraad Theuwissen, Jacques Lacaze, Lydia Laffont-Dantras, Julien Zollinger, Dominique Daloz. Effect of $\mathrm{Ce}$ and $\mathrm{Sb}$ on Primary Graphite Growth in Cast Irons. Transactions of the Indian Institute of Metals, 2012, vol. 65 ( $\mathrm{n}^{\circ}$ 6), pp. 707-712. 10.1007/s12666-012-0203-0 . hal-03528887

\section{HAL Id: hal-03528887 https://hal.science/hal-03528887}

Submitted on 17 Jan 2022

HAL is a multi-disciplinary open access archive for the deposit and dissemination of scientific research documents, whether they are published or not. The documents may come from teaching and research institutions in France or abroad, or from public or private research centers.
L'archive ouverte pluridisciplinaire HAL, est destinée au dépôt et à la diffusion de documents scientifiques de niveau recherche, publiés ou non, émanant des établissements d'enseignement et de recherche français ou étrangers, des laboratoires publics ou privés. 


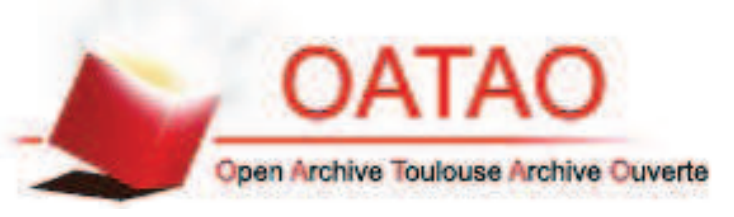

\section{Open Archive Toulouse Archive Ouverte (OATAO)}

OATAO is an open access repository that collects the work of Toulouse researchers and makes it freely available over the web where possible.

This is an author-deposited version published in: http://oatao.univ-toulouse.fr/ Eprints ID: 8716

To link to this article : DOI:10.1007/s12666-012-0203-0

URL : http://dx.doi.org/10.1007/s12666-012-0203-0

\section{To cite this version:}

Theuwissen, Koenraad and Lacaze, Jacques and Laffont-Dantras, Lydia and Zollinger, Julien and Daloz, Dominique Effect of $\mathrm{Ce}$ and $\mathrm{Sb}$ on Primary Graphite Growth in Cast Irons. (2012) Transactions of the Indian Institute of Metals, vol. 65 (n 6). pp. 707-712. ISSN 0972-2815

Any correspondence concerning this service should be sent to the repository administrator: staff-oatao@listes.diff.inp-toulouse.fr 


\title{
Effect of Ce and Sb on Primary Graphite Growth in Cast Irons
}

\author{
K. Theuwissen · J. Lacaze $\cdot$ L. Laffont $\cdot$ \\ J. Zollinger $\cdot$ D. Daloz
}

\begin{abstract}
It is well-known that if certain trace elements are present in cast iron melts the morphology of the graphite precipitates can be altered. In order to understand the effect of doping elements on primary growth of graphite, pure $\mathrm{Fe}-\mathrm{Sb}$ alloys were prepared by induction melting. They were then placed in graphite crucibles and heated to a temperature above the $\mathrm{Fe}-\mathrm{C}$ eutectic so that the charge became saturated in carbon and melted. To obtain $\mathrm{Fe}-\mathrm{Ce}$ alloys, metallic $\mathrm{Ce}$ was added at the bottom of a graphite crucible and covered with iron, and then heated as for the $\mathrm{Fe}-\mathrm{Sb}$ charge. In both cases, the melt was then cooled and held slightly above the eutectic temperature so that primary graphite crystals, which had nucleated on the crucible walls and then detached from it, could grow freely in the melt. The influence of the added elements on graphite growth was revealed by the change in the shape and distribution of the crystals compared to those obtained in similar experiments carried out with pure Fe. The experiments were made in air and vacuum so as to point out possible interactions between the elements present in the melt and oxygen.
\end{abstract}

Keywords Graphite growth · Cast iron - Trace elements

K. Theuwissen $(\bowtie) \cdot$ J. Lacaze $\cdot$ L. Laffont

CIRIMAT, Université de Toulouse, ENSIACET, BP 44362 ,

31030 Toulouse Cedex 4, France

e-mail: koenraad.theuwissen@ensiacet.fr

J. Zollinger · D. Daloz

Institut Jean Lamour, Département SI2M, CNRS - Nancy-

Université, Ecole des Mines de Nancy, Parc de Saurupt,

CS14234, 54042 Nancy, France

\section{Introduction}

Graphitic cast irons present a wide range of mechanical properties that depend strongly on the shape of the graphite precipitates. The most common structures are lamellar and spheroidal graphite and the change from one form to the other is achieved by adding small amounts of $\mathrm{Mg}$ or Ce to the melt. Graphite growth mechanism is thus very sensitive to tiny changes in melt composition.

Besides these spheroidizing agents, it is known that other elements can affect graphite growth [1] and lead to degenerate graphite structures. The modification of graphite shape by the introduction of foreign elements to the melt can be indirect, i.e. due to an interaction with other elements present in the melt. Researchers have suggested this for the case of elements such as Mg which can combine with sulphur and oxygen, leading to spheroidal graphite [2].

Other elements such as $\mathrm{Bi}, \mathrm{Cd}, \mathrm{Sn}$ and $\mathrm{Sb}$ have been mentioned to directly affect graphite growth [3]. In heavysection castings where long solidification times are needed, elements such as $\mathrm{Ca}$ and $\mathrm{Ce}$ have been reported to promote degenerate spheroidal graphite [4].

As part of a project devoted to the understanding of the effect of trace elements on graphite degeneracy, this work focuses on morphological changes of graphite precipitates in pure $\mathrm{Fe}-\mathrm{C}$ alloys containing small amounts of specific additions to complete previous experiments on commercial irons [5].

\section{Experimental}

Pure $\mathrm{Fe}$ and $\mathrm{Sb}$ were used to prepare synthetic alloys by induction melting under argon atmosphere. This method 
was chosen in order to obtain alloys of homogeneous composition and to limit oxidation phenomena. Two heats of $50 \mathrm{~g}$ of $\mathrm{Fe}-0.5 \% \mathrm{Sb}$ (at.\%), were prepared to be used for primary graphite growth experiments. Samples of $\sim 1 \mathrm{~g}$ of this alloy were placed in graphite crucibles (crucibles ALPHA AR6247 designed for chemical analysis of oxygen and nitrogen). Metallic Ce was placed at the bottom of graphite crucibles and pure Fe was placed over it in order to prepare $\mathrm{Fe}-2 \% \mathrm{Ce}$ alloy. For some of the experiments, a lid made of graphite of nuclear purity was placed on top of the material and $\mathrm{MgO}$ adhesive (COTRONICS Resbond 919 high-resistance ceramic adhesive) was used to seal the crucibles to limit volatilization of the elements.

The crucibles with the charge material were then positioned in an alumina tube located within a cylindrical resistance furnace. The experiments consisted in heating the charge to $1,350{ }^{\circ} \mathrm{C}$ and holding it at that temperature for $10 \mathrm{~min}$. During this stage, the material became carbon saturated and the charge melted. The samples were then cooled at $20{ }^{\circ} \mathrm{C} / \mathrm{min}$ to $1,180{ }^{\circ} \mathrm{C}$-i.e. a temperature slightly above the $\mathrm{Fe}-\mathrm{C}$ eutectic temperature-and maintained at this temperature for $30 \mathrm{~min}$. During this second stage, growth of primary graphite precipitates took place. In a last stage, the samples were quenched by air blowing at $660{ }^{\circ} \mathrm{C} / \mathrm{min}$. A schematic of the experimental facility is shown in Fig. 1.

Sections of the samples were prepared for metallographic observations. The shape and distribution of the graphite precipitates in the samples were examined in order to study the influence of $\mathrm{Ce}$ and $\mathrm{Sb}$ on graphite growth. A pure $\mathrm{Fe}-\mathrm{C}$ alloy without any added elements underwent

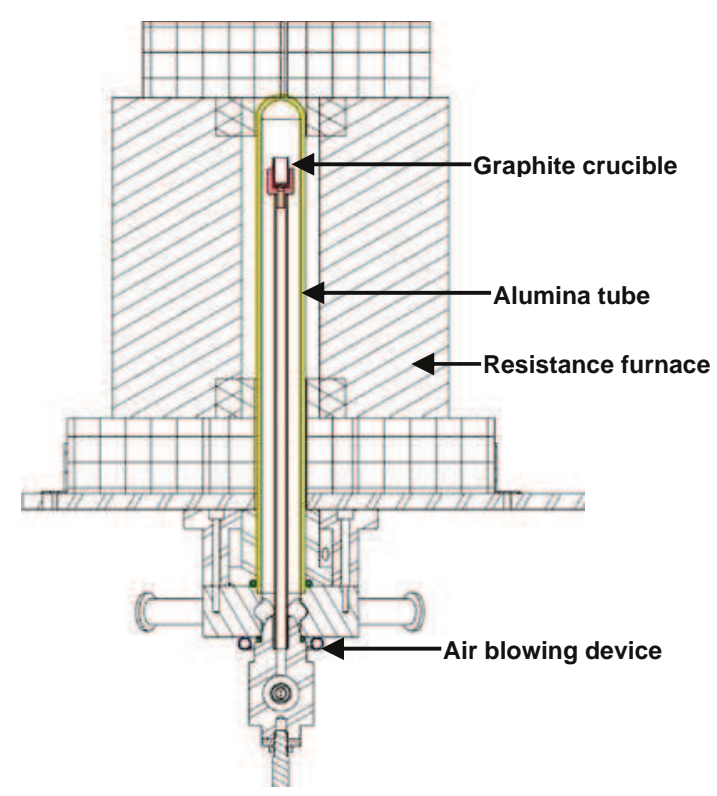

Fig. 1 Schematic of the experimental facility the same treatment and was used as a reference for comparison.

In a first series, the experiments were carried out with the alumina tube open to ambient air. In a second series, the experiments were repeated in medium vacuum $\left(10^{-3}\right.$ mbar) to evidence possible effect of oxygen. Finally, in order to reveal the influence of the cooling rate on graphite precipitation, the last stage of the treatment, i.e. air quenching was replaced by slower cooling rates of $200{ }^{\circ} \mathrm{C} /$ $\min$ and $6{ }^{\circ} \mathrm{C} / \mathrm{min}$.

\section{Results and Discussion}

In the case of pure Fe charge, primary graphite precipitates consisted in large lamellae, see Fig. 2, found at the top of the samples. This suggests that after nucleation and growth along the crucible walls the precipitates detached and floated to the upper part of the sample due to density difference between graphite and liquid iron as has already been reported [6].

The rest of the samples contains some ex-austenite dendrites and small graphite precipitates, namely some nodules but mainly undercooled graphite associated to exaustenite in a fine eutectic. These latter features certainly formed during the final stage of the thermal cycle when the sample was rapidly cooled. Thus interest will rather be focused on the large primary graphite precipitates which grew freely in the melt during the second stage of the thermal cycle. In the case of pure $\mathrm{Fe}-\mathrm{C}$ samples, graphite lamellae were 300-500 $\mu \mathrm{m}$ long, thin with few branchings and a very regular outer surface.

\subsection{Effect of Ce Additions}

The first experiments on Ce-bearing samples were conducted in air without lid. The graphite lamellae (Fig. 3a)

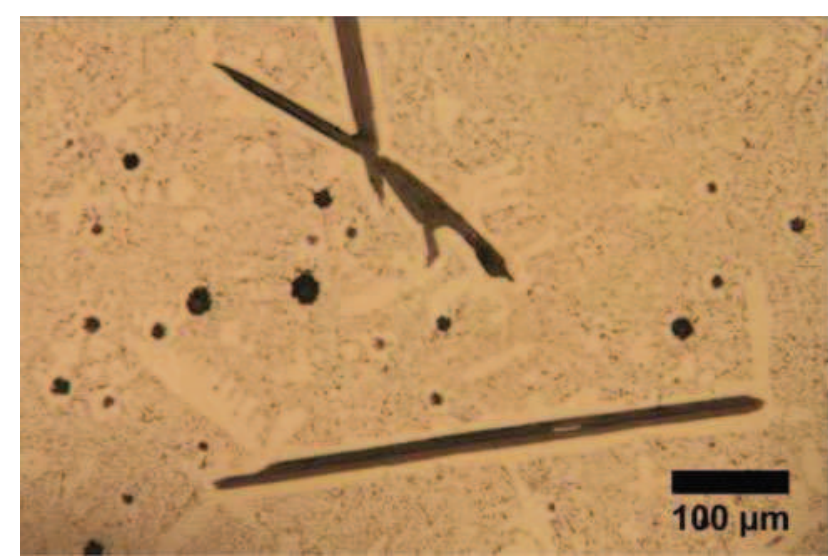

Fig. 2 Graphite lamellae in a pure $\mathrm{Fe}-\mathrm{C}$ sample melted in air 

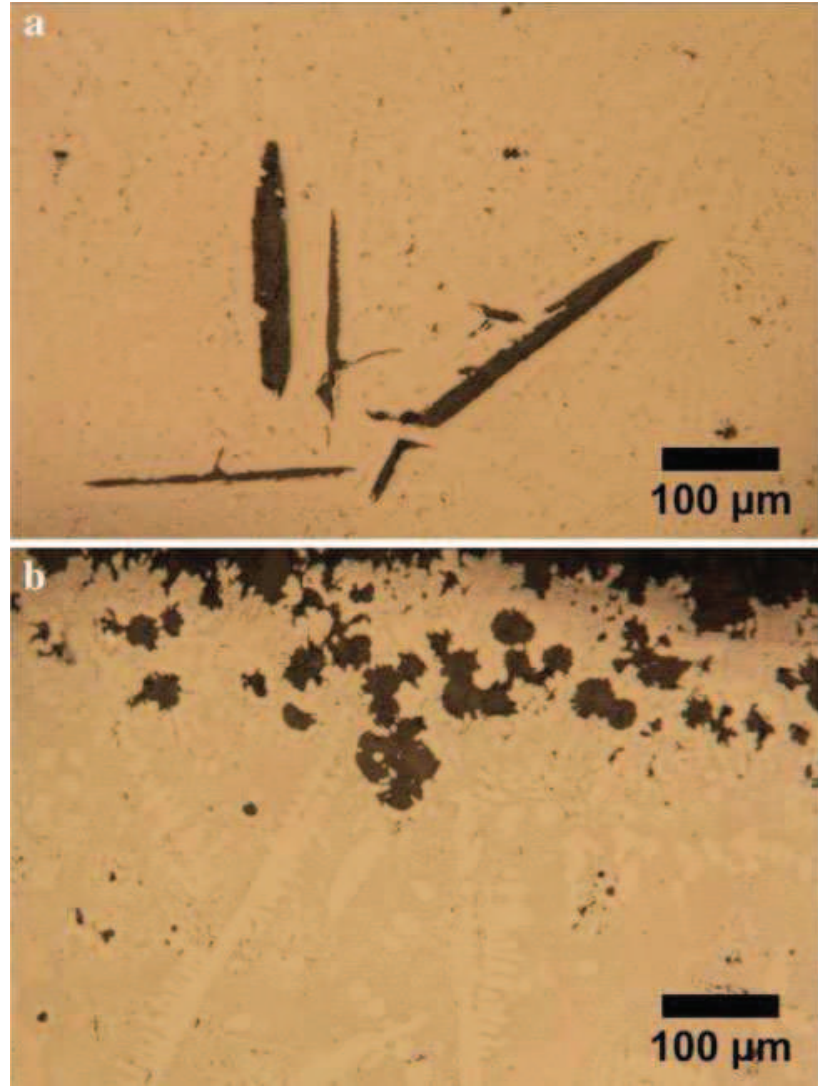

Fig. 3 Graphite precipitates in $\mathrm{Fe}-\mathrm{C}-\mathrm{Ce}$ alloys melted in air (a) and vacuum (b)

were shorter (100-200 $\mu \mathrm{m})$ and thicker than the ones in the reference sample. While Ce is known to be a spheroidizing agent as mentioned before, no spheroids could be observed. This could be due to the presence of an important amount of oxygen that led to $\mathrm{Ce}$ oxidation or to volatilization of $\mathrm{Ce}$ during the experiment.

To check the first hypothesis, the same experiments were then carried out in medium vacuum. The results are shown in Fig. 3b where partially formed graphite spheroids were found at the upper surface of the samples, within a $250 \mu \mathrm{m}$ thick strip. This proves that lowering the oxygen content in the chamber has a significant influence on the graphite morphology as has already been shown by observations of graphite spherulites in pure $\mathrm{Fe}-\mathrm{C}-\mathrm{Si}$ alloys melted in high vacuum [7, 8] and confirms that the effect of $\mathrm{Ce}$ as spheroidizer must firstly depend on the presence of $\mathrm{O}$. That is to say, $\mathrm{O}$ hinders the mechanism responsible for the development of spheroidal graphite. $\mathrm{Ce}$, by scavenging small amounts of oxygen in the melt, leads to the formation of spheroids as in the present vacuum conditions.

The second hypothesis, i.e. that Ce could have volatilized during the experiments, seemed also plausible. To prevent this, the crucibles were sealed with a graphite lid and $\mathrm{MgO}$ adhesive. After drying, this ceramic adhesive
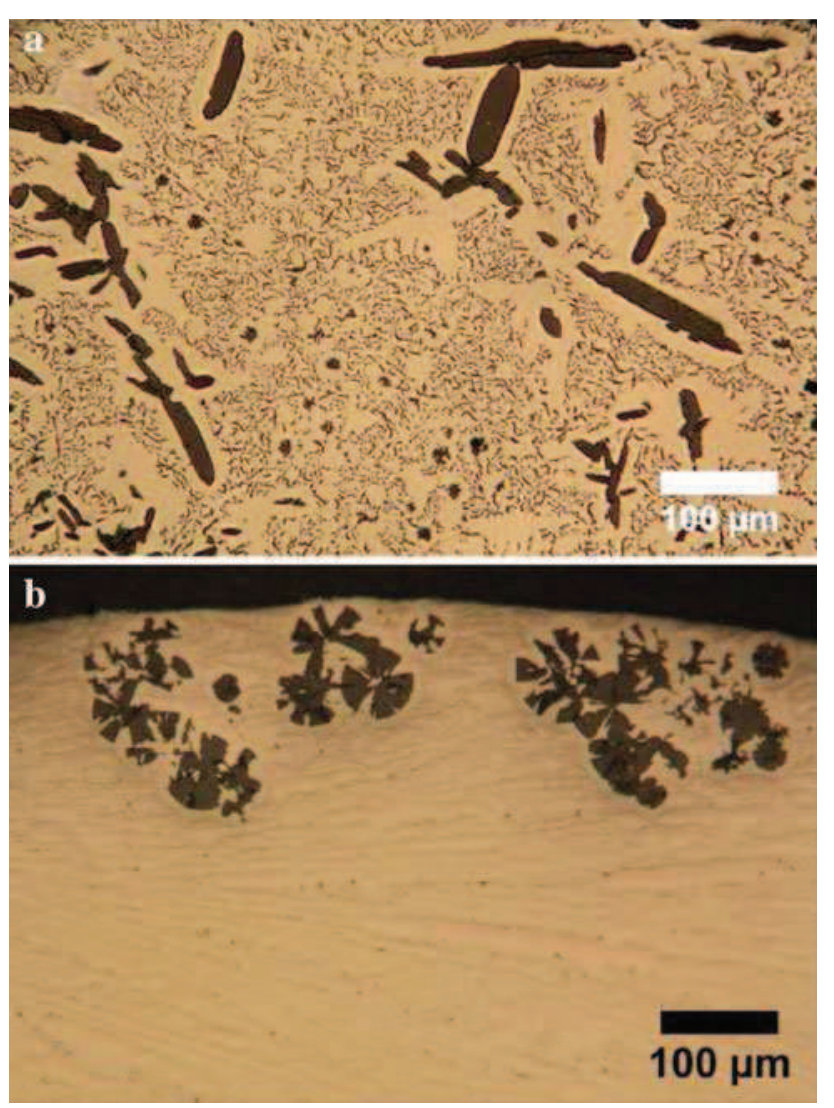

Fig. 4 Graphite precipitates in $\mathrm{Fe}-\mathrm{C}-\mathrm{Ce}$ alloys prepared in sealed crucibles in air (a) and vacuum (b)

formed a completely inert cap and experiments were repeated.

Vacuum experiments on sealed crucibles led to both fully and partially formed graphite spheroids (Fig. 4b) which were once again found settling in the upper part of the samples. No graphite was found in the rest of the samples, except on some of their outer surfaces where a $20 \mu \mathrm{m}$ thick graphite layer developed (Fig. 5). Some spheroidal graphite precipitates could be observed connected to this layer and this might be evidence of the first stage of growth of spheroids from the crucible walls.

It is worth mentioning that after these experiments, yellow powder was found at the bottom of the crucible. This is probably $\mathrm{Ce}$ oxide, revealing that not all the metallic Ce was dissolved in the melt and that only small amounts of $\mathrm{Ce}$ were needed to change the graphite structure.

A further experiment was thus carried out in air with a sealed crucible. The microstructure of this sample did not present any spheroids (Fig. 4a), but showed short and thick graphite lamellae with a platelet-like structure. This suggests that the sealing is porous so that some oxygen can enter the crucible and react with cerium when the chamber is not evacuated. It has not yet been possible to measure the 


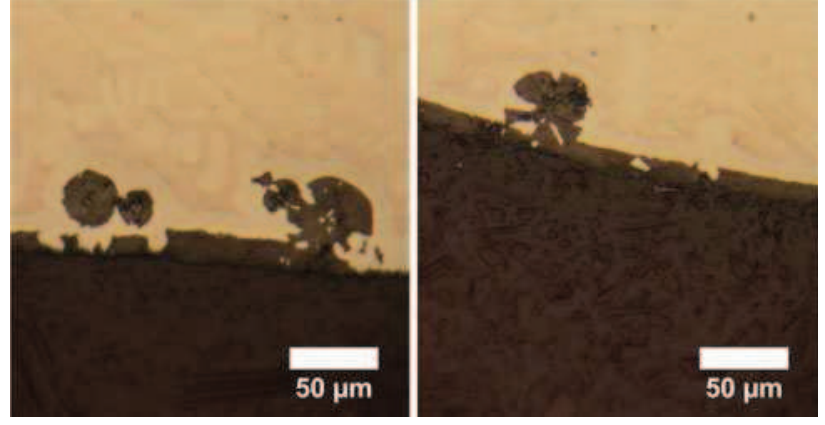

Fig. 5 Graphite spheroids in vacuum melted $\mathrm{Fe}-\mathrm{C}-\mathrm{Ce}$ alloys, growing at the edges of the samples

oxygen content of these various samples, but this would be of interest as this could possibly explain that the plates in Fig. 4a are shorter and thicker than those in Fig. 3a. It seems established however that sealing does limit the loss of cerium from the sample.

\subsection{Effect of Sb Additions}

For limiting possible loss of antimony, sealed crucibles were used for experiments with Sb-bearing alloys. Metallographic sections of the samples prepared in air and vacuum (Fig. 6) showed long curved lamellae with frequent branching as compared to the reference $\mathrm{Fe}-\mathrm{C}$ samples (Fig. 2). This could mean that $\mathrm{Sb}$ promotes both graphite bending and branching.

The lamellae also presented frequent direction changes giving them an overall wavy aspect. The reason for this could be that $\mathrm{Sb}$ enters the graphite lattice thus promoting growth defects as suggested in the past [9] following mechanisms such as impurity induced twinning reported for silicon in Al-Si alloys [10]. Furthermore, the curved aspect of the lamellae seems to be increased in vacuum experiments. In this case lamellae are longer and have an increased bending radius (compare Fig. 6a and b).

\subsection{Influence of the Cooling Rate}

The cooling rate is known to have a major influence on graphite precipitation $[11,12]$. It thus seemed of interest to complement the above results with observations on samples cooled at $200{ }^{\circ} \mathrm{C} / \mathrm{min}$ and $6{ }^{\circ} \mathrm{C} / \mathrm{min}$ after holding at $1,180{ }^{\circ} \mathrm{C}$.

At a slow cooling rate of $6{ }^{\circ} \mathrm{C} / \mathrm{min}$, Sb still seemed to promote curvature of the whole lamellae but their outer surface appeared more irregular than for cooling at high cooling rate or an intermediate cooling rate of $200{ }^{\circ} \mathrm{C} / \mathrm{min}$, compare Fig. 7a, b. This could possibly be partly attributed to subsequent carbon deposition in the solid state during cooling after solidification, closely related to the fact that

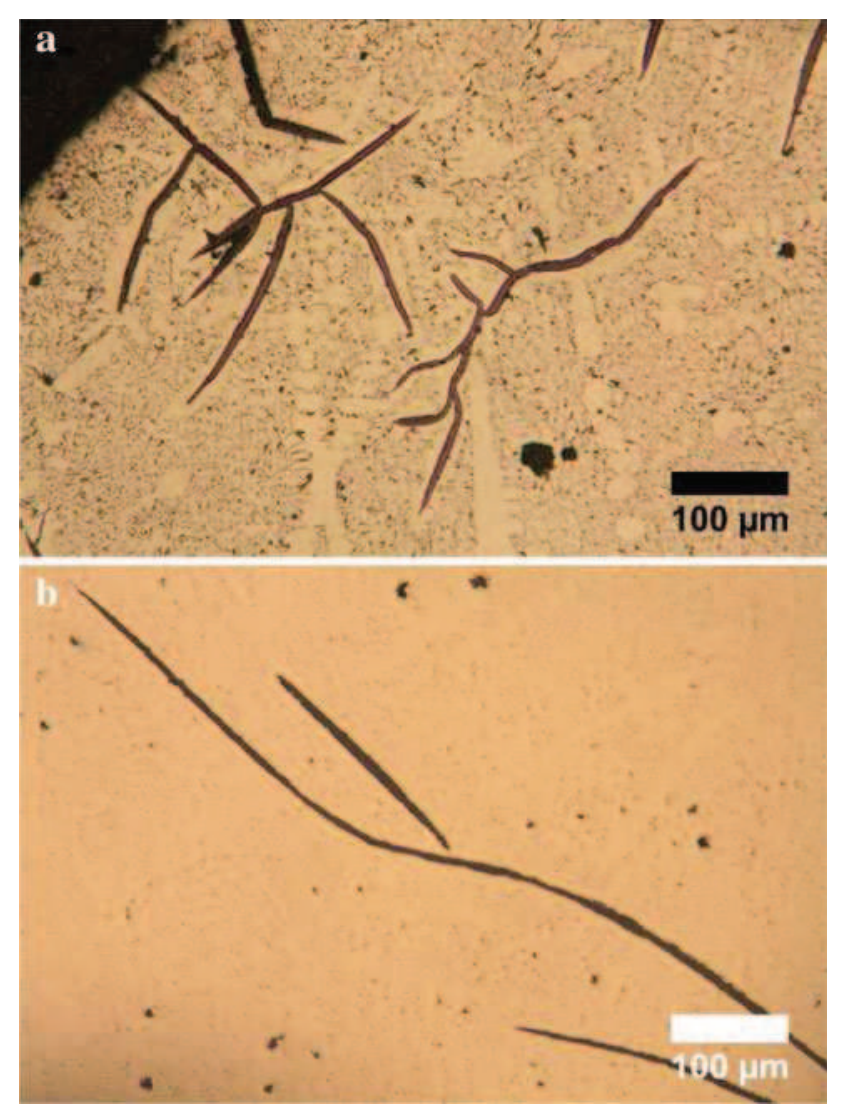

Fig. 6 Graphite precipitates in $\mathrm{Fe}-\mathrm{C}-\mathrm{Sb}$ alloys prepared in sealed crucibles in air (a) and vacuum (b)

the fineness of the undercooled graphite decreased with the cooling rate. However, this needs some further investigation as roughening of the outer graphite surface has been reported to be associated to doping of graphite with metallic elements in the case of commercial cast irons [5].

In the case of vacuum melted slowly cooled Ce-bearing samples, imperfect primary graphite spheroids were found at the top of the samples, similarly to what was obtained with high cooling rates. In the rest of the samples graphite spheroids of about $25 \mu \mathrm{m}$ were found (Fig. 8b, c). These were surrounded by a ferrite halo. A similar structure was obtained at $200{ }^{\circ} \mathrm{C} / \mathrm{min}$ (Fig. 8a) but graphite spheroids were smaller (diameter: $10 \mu \mathrm{m}$ ) and the halos surrounding them were thinner. In both cases, the cooling rate did not seem to affect the growth of the irregular primary graphite precipitates found in the upper part of the samples. On the other hand, the differences observed between the size of the spheroids found in the rest of the samples and the thickness of the halos surrounding them at different cooling rates suggest that their growth happened in a latter stage involving both eutectic solidification and solid state decomposition of the matrix. These results confirm the spheroidizing action of $\mathrm{Ce}$ when compared to the bulk of 

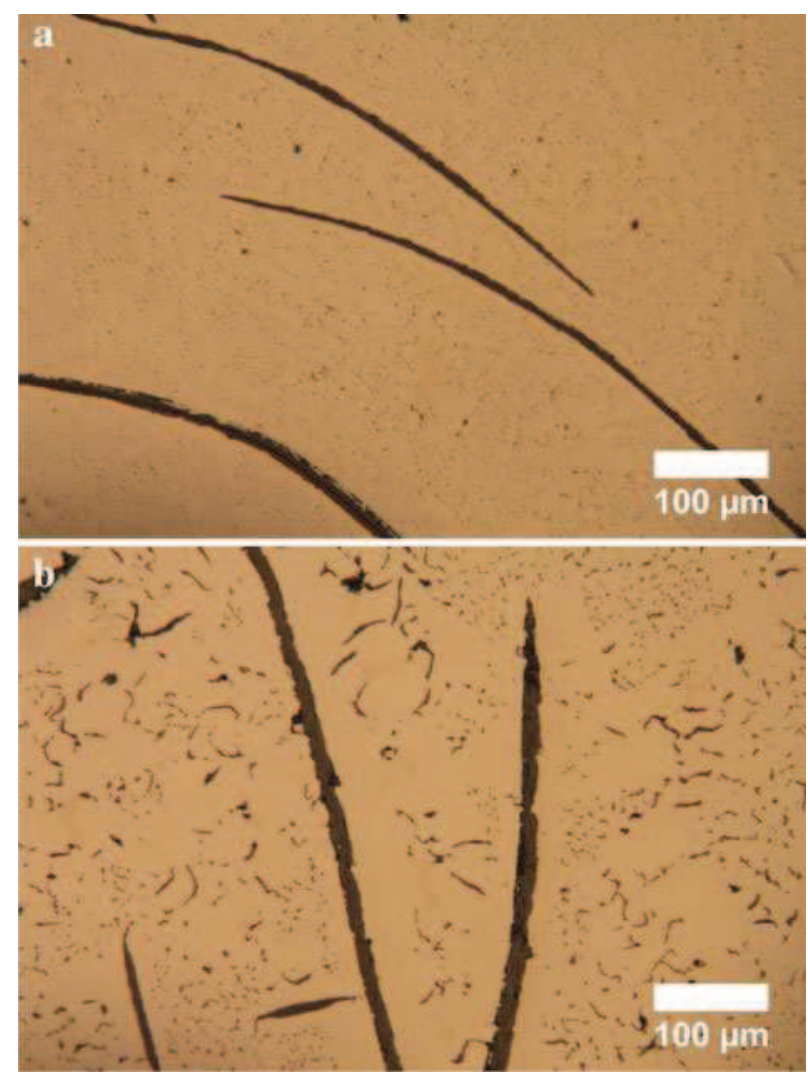

Fig. 7 Sections of vacuum melted $\mathrm{Fe}-\mathrm{C}-\mathrm{Sb}$ alloys cooled at $200{ }^{\circ} \mathrm{C} /$ $\min (\mathbf{a})$ and $6{ }^{\circ} \mathrm{C} / \min (\mathbf{b})$

the Sb-bearing samples where no spheroids were found (Fig. 7).

\section{Conclusion}

Completing previous studies on commercial cast irons, primary graphite precipitation experiments on pure alloys showed the effect of individual elements on graphite growth. In this study, it was shown that small amounts of $\mathrm{Ce}$ and $\mathrm{Sb}$ could modify the morphology of graphite precipitates in cast iron melts. For melting and solidification in air, $\mathrm{Ce}$ additions led to thick graphite platelets while $\mathrm{Sb}$ additions gave rise to long, curved and bent lamellae.

In order to deconvolute the effects of these elements and those of oxygen, medium vacuum experiments were carried out. Graphite spheroids were formed in Ce-bearing samples whereas vacuum melted Sb-bearing samples led to long and bent lamellae. These observations suggest that $\mathrm{Ce}$ has an indirect effect on graphite growth, e.g. scavenging oxygen, while $\mathrm{Sb}$ seems to have a more direct action on the graphite structure leading to bent irregular primary graphite precipitates. Even if its effect might be amplified by the presence of other elements in commercial melts, Sb alone
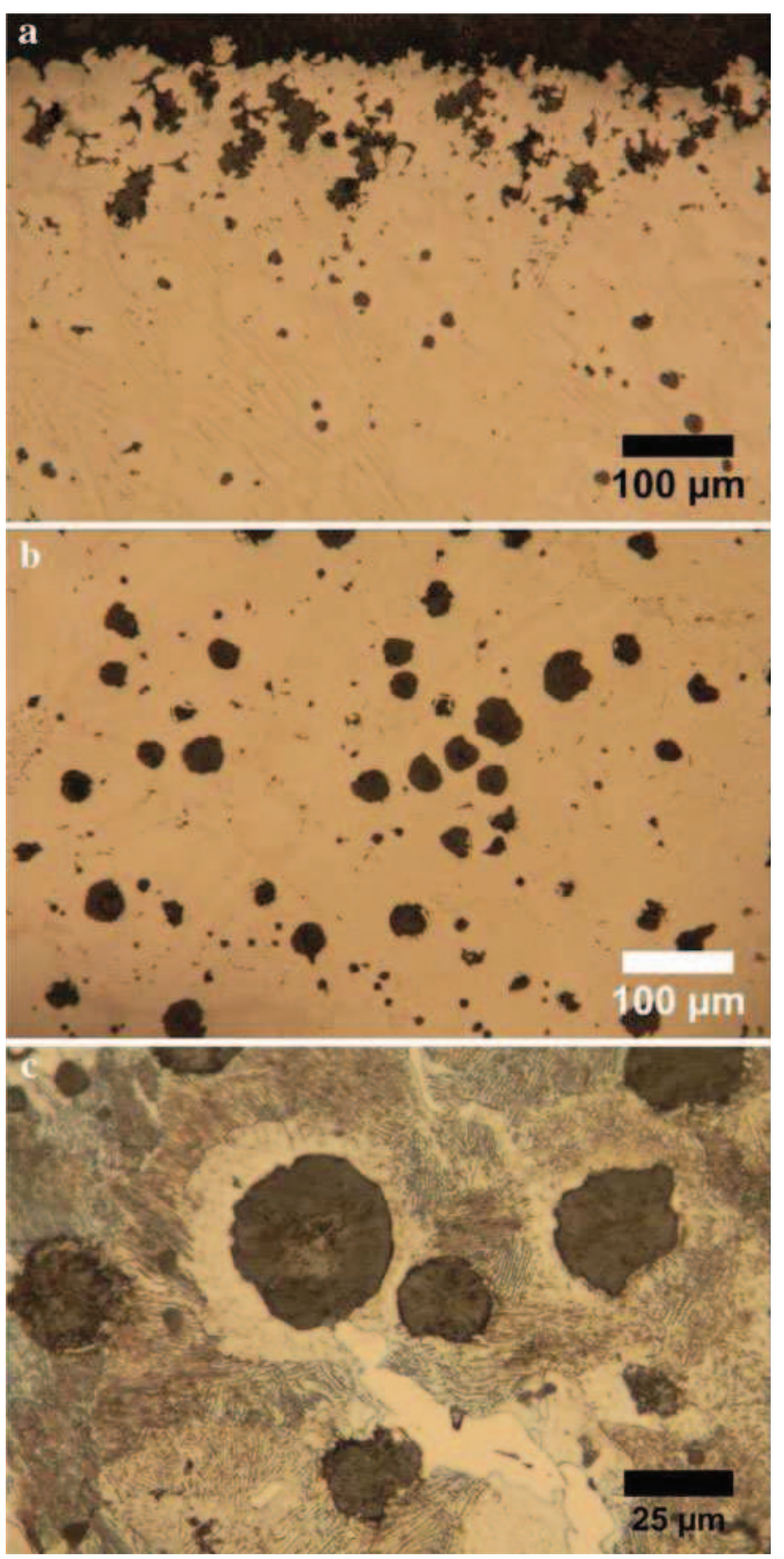

Fig. 8 Graphite spheroids in vacuum melted $\mathrm{Fe}-\mathrm{C}-\mathrm{Ce}$ alloys cooled at $200{ }^{\circ} \mathrm{C} / \mathrm{min}$ (a) and $6{ }^{\circ} \mathrm{C} / \mathrm{min}$ before (b) and after Nital etching (c)

could account, at least to some extent, for graphite shape modification in cast irons.

Acknowledgments G. Lesoult and J.-C. Salabura are greatly acknowledged for discussion and for designing the experimental rig respectively.

\section{References}

1. Lux B, Giessereiforschung 22 (1970) 65 (in English).

2. Morrogh H, J Iron Steel Inst 206 (1968) 1.

3. Javaid A, and Loper C R, AFS Trans 103 (1995) 135. 
4. Wallace J F, AFS Trans 83 (1975) 363.

5. Valle N, Theuwissen K, Sertucha J, and Lacaze J, IOP Conference Series: Materials Science and Engineering (MSE) 27 (2012) 012026.

6. Wetterfal S E, Fredriksson H, and Hillert M, J Iron Steel Inst (1972) 323.

7. Keverian J, Taylor H F, and Wulff J, Am Foundry 23 (1953) 85.
8. Dhindaw B, and Verhoeven J D, Metall Trans A 11A (1980) 1049.

9. Double D D, and Hellawell A, Acta Metall Mater 43 (1995) 2435.

10. Lu S-Z, and Hellawell A, Metall Mater Trans A 18 (1987) 1721.

11. Vigneron B, C R Acad Sci série C 270 (1970) 1941.

12. Park J S, and Verhoeven J D, Metall Mater Trans A 27A (1996) 2740. 